\title{
Pengaruh Bahan Organik dan Suhu Pengeringan terhadap Ketahanan Hidup Aspergillus niger dalam Pupuk Pelet Bio-fosfat
}

The Effect of Organic Matter and the Drying Temperature on the Aspergillus niger Survivability in the Bio-phosphate Pellet Fertilizer

\author{
Yudi Sastro $^{1 *}$, Donny Widianto ${ }^{2}$, Irfan D. Prijambada ${ }^{2}$ \\ ${ }^{I}$ Balai Pengkajian Teknologi Pertanian Jakarta \\ E-mail: yudis_bkl2001@yahoo.com *Penulis untuk korespondensi \\ ${ }^{2}$ Fakultas Pertanian UGM, Yogyakarta
}

\begin{abstract}
This research was aimed to investigate the effect of organic matter and drying temperature on Aspergillus niger survivability in the rock phosphate pellet fertilizer namely bio-phosphate. The research was arranged by a completely randomized design $3 \times 3 \times 6$. Addition of the mixing of tapioca waste, rice bran, and starch (BOC) and the humic substance (BH) in the bio-phosphate, and its drying temperature (SP) were the treatments. Aspergillus niger inoculums survivability in the bio-phosphate was determined using plating methods. The result showed that the addition of BOC decreased amount of $A$. niger in the bio-phosphate up to $28.0 \%$, while the $\mathrm{BH}$ increased the amount of $A$. niger up to $24.4 \%$. The ideal drying temperature of bio-phosphate pellet fertilizer was $60^{\circ} \mathrm{C}$.
\end{abstract}

Key words: organic matter, drying temperature, Aspergillus niger, bio-phosphate

Diterima: 26 Februari 2007, disetujui: 30 Maret 2007

\section{Pendahuluan}

Empat prasyarat utama keberhasilan pengembangan inokulum mikroba secara komersial, yaitu dapat diproduksi secara masal, berbiaya murah, memiliki tingkat keseragaman tinggi, dan mudah untuk diaplikasikan (Walter \& Pauu, 1993). Penelitian mengenai inokulum mikroba yang berperan dalam peningkatan ketersediaan hara untuk tanaman telah banyak dilakukan, diantaranya penambat N-bebas (Rao, 1976; Balasubramanian et al., 1980; Rao, 1982) dan pelarut fosfat (Banik \& Dey, 1982; Thomas et al., 1985; Goenadi \& Saraswati, 1993; Goenadi, 1996; Zhang et al., 1997; Widiastuti et al., 2000)

Inokulum dan formula penambat $\mathrm{N}$ bebas, diantaranya rhizobium, telah berhasil dikembangkan secara komersial dan diaplikasikan secara luas. Sementara itu, pengembangan inokulum pelarut fosfat masih banyak mengalami hambatan, terutama dalam hal formulasi, keseragaman, kemudahan aplikasi dan efektivitas pada saat diaplikasikan. Hingga saat ini, efektivitas mikroba pelarut fosfat (MPF) dalam meningkatkan penyediaan fosfor untuk tanaman bervariasi sangat lebar (Salih et al., 1989; Gaind \& Gaur, 1991; Rao, 1994; Kim et al., 1997; Elfiati et al., 1999). Pengembangan teknologi formulasi MPF yang memiliki keseragaman tinggi, mudah diaplikasikan, dan efektif dalam menyediakan fosfor untuk tanaman masih perlu dikembangkan.

Serangkaian penelitian dilakukan guna mengembangkan formula pupuk bio-fosfat, yaitu formula pupuk pelet gabungan inokulum MPF yang dalam hal ini diwakili oleh Aspergillus niger, batuan fosfat sebagai sumber fosfat, dan bahan organik yang berperan sebagai bahan pembawa (carier) sekaligus sumber nutrisi untuk A. niger. Dalam mengembangkan pupuk pelet bio-fosfat tersebut maka tahapan pertama yang harus 
dikaji adalah kemampuan inokulum A. niger tersebut untuk bertahan hidup pada saat digabungkan dengan batuan fosfat dan dibuat menjadi pupuk pelet bio-fosfat. Penelitian ini bertujuan untuk menguji peran bahan organik, bahan humat, dan suhu pengeringan terhadap ketahanan hidup inokulum $A$. niger pada saat digabungkan dengan batuan fosfat dan buat menjadi pupuk pelet bio-fosfat.

\section{Metode Penelitian}

\section{Bahan pupuk pelet bio-fosfat}

Bahan pupuk bio-fosfat, meliputi 1) batuan fosfat Christmas Island lolos saringan 100 mesh, 2) bahan organik campuran onggok (limbah industri tapioka) 69,5\%, sekam 30\%, dan pati $0,5 \%(\mathrm{~b} / \mathrm{b})(\mathrm{BOC})$, masing-masing lolos saringan 100 mesh, 3) bahan humat (BH) diekstraksi dari gambut saprik yang berasal dari Pangkoh, Kalimantan Tengah menggunakan $\mathrm{NaOH}$ (Merck) 0,2 M.

\section{Pembuatan pupuk pelet bio-fosfat}

Pembuatan pupuk pelet bio-fosfat dilakukan dengan mencampur batuan fosfat dengan bahan organik steril dengan perbandingan sesuai perlakuan. Setelah dingin, pada setiap bahan tercampur diinokulasi spora A. niger secara merata dengan kerapatan 10 colony forming units (CFU) per gram bahan pupuk. Sebagai bahan perekat ditambahkan kanji yang dibuat dari tepung tapioka $(10 \mathrm{~g}$ pati..$^{-1}$ air) sebanyak $10 \mathrm{ml}$ per 100 gram bahan pelet. Pemeletan pupuk dilakukan menggunakan mesin pemelet dengan ukuran pelet $5 \times 3 \mathrm{~mm}$. Pelet batuan fosfat selanjutnya dikeringkan sesuai perlakuan.

\section{Perancangan percobaan}

Percobaan diatur menggunakan RAL pada faktorial 3 X3X6. Jumlah penyertaan BOC dan $\mathrm{BH}$, dan suhu pengeringan pupuk (SP) dijadikan sebagai faktor perlakuan. Perlakuan BOC terdiri tiga aras, yaitu tanpa BOC, BOC $20 \%$, dan $40 \%$ (b/b). Perlakuan BH terdiri tiga aras, yaitu tanpa $\mathrm{BH}, \mathrm{BH} 10 \%$, dan $20 \%$ (v/b). Perlakuan suhu pengeringan terdiri enam aras, yaitu suhu $50,60,70,80,90$, dan $100^{\circ} \mathrm{C}$.
Masing-masing kombinasi perlakuan diulang sebanyak tiga kali.

\section{Pengujian ketahanan hidup $A$. niger}

Jumlah inokulum A. niger yang dapat bertahan hidup dalam pupuk bio-fosfat diamati setelah perlakuan pengeringan pupuk. Penghitungan jumlah $A$. niger dilakukan dengan cara menumbuhkannya pada medium Potatoes Dextrose Agar (PDA) menggunakan metode tebaran pada cawan petri. Persentase penurunan jumlah jamur dihitung dengan formula sebagai berikut:

$$
\begin{aligned}
& \text { A. } \\
& \begin{array}{c}
\text { niger yang bertahan } \\
\text { hidup }(\%)
\end{array}
\end{aligned}=\frac{\mathrm{A}-\mathrm{B}}{\mathrm{A}} \times 100
$$

$A=\log$ jumlah spora hidup sebelum pengeringan $\mathrm{B}=\log$ jumlah spora hidup setelah pengeringan

\section{Hasil dan Pembahasan}

Perlakuan yang diujikan terhadap daya tahan hidup inokulum A. niger yang disertakan dalam formula pupuk pelet bio-fosfat tidak terdapat interaksi yang nyata $(\mathrm{P} \geq 0,05)$ antara ketiga faktor, kecuali antara perlakuan bahan organik campuran onggok, sekam, dan pati (BOC) dan suhu pengeringan $(\mathrm{P} \leq 0,05)$. Oleh sebab itu, pembahasan hasil penelitian diarahkan pada pengaruh tunggal masingmasing faktor perlakuan dan faktor perlakuan yang secara statistik menunjukkan interaksi yang nyata.

\section{Pengaruh bahan organik}

Hasil pengujian menunjukkan bahwa bahan organik yang disertakan dalam formula pupuk pelet bio-fosfat berpengaruh terhadap ketahanan hidup A. niger selama proses pembuatan pupuk. Semakin tinggi jumlah bahan organik maka jumlah A. niger yang mampu bertahan hidup nyata semakin rendah (Gambar 1). Pengaruh bahan organik terhadap penurunan jumlah $A$. niger tersebut terlihat jelas pada perlakuan pengeringan pupuk pelet bio-fosfat pada suhu 90 dan $100^{\circ} \mathrm{C}$ (Tabel 1). Pada pupuk pelet bio-fosfat tanpa disertai bahan organik, inokulum $A$. niger tetap mampu bertahan hidup hingga suhu $100^{\circ} \mathrm{C}$. 
Penurunan jumlah A. niger pada perlakuan penyertaan bahan organik tersebut diduga karena tingginya tingkat kadar air dan ketersediaan nutrisi dalam pupuk bio-fosfat. Activity of water (aw) A. niger adalah 0,65 $(6,5 \%)$ (Atlas \& Bartha, 1987). Kadar air pupuk yang melebihi nilai aw A. niger dan tingginya ketersediaan nutrisi diduga menyebabkan terjadinya perkecambahan spora A. niger sesaat setelah digabungkan dengan batuan fosfat dan bahan organik. Perubahan bentuk $A$. niger dari bentuk tahannya (spora) menjadi bentuk tidak tahan (vegetatif) menyebabkan penurunan tingkat ketahanannya terhadap suhu pengeringan pupuk.

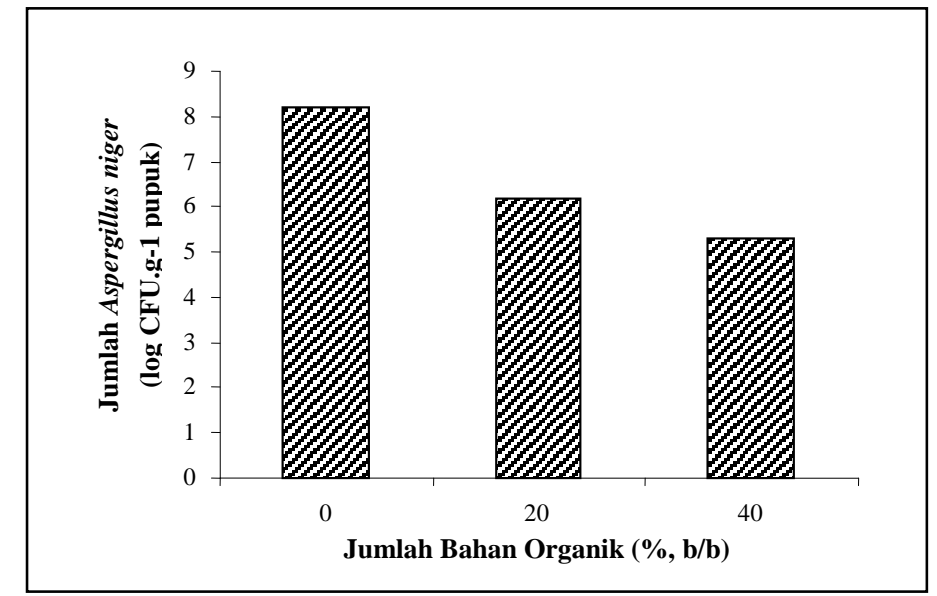

Gambar 1. Pengaruh penyertaan bahan organik campuran onggok, sekam, dan pati (BOC) terhadap ketahanan hidup inokulum Aspergillus niger selama pembuatan pupuk pelet bio-fosfat.

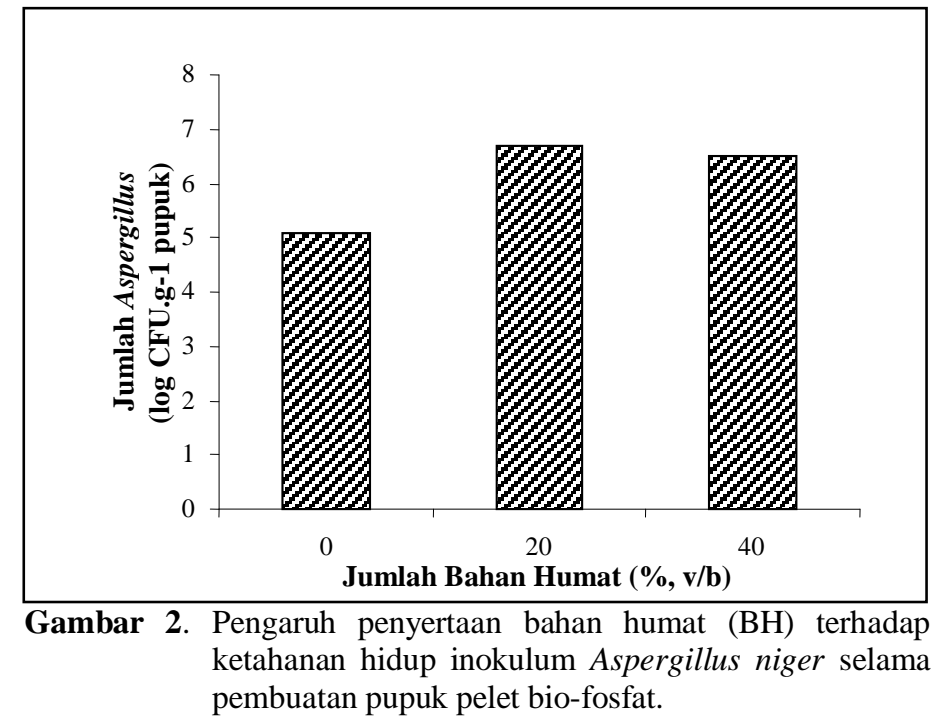

Tabel 1. Pengaruh interaksi antara bahan organik campuran onggok, sekam, dan pati (BOC) serta suhu pengeringan terhadap ketahanan hidup Aspergillus niger selama proses pembuatan pupuk pelet bio-fosfat.

\begin{tabular}{ccccccc}
\hline \hline BOC & \multicolumn{7}{c}{ Suhu pengeringan ( $\mathbf{C})$} \\
\cline { 2 - 7 }$(\mathbf{\%})$ & $\mathbf{5 0}$ & $\mathbf{6 0}$ & $\mathbf{7 0}$ & $\mathbf{8 0}$ & $\mathbf{9 0}$ & $\mathbf{1 0 0}$ \\
\hline \hline $\mathbf{0}$ & $8,93 \mathrm{a}$ & $9,13 \mathrm{a}$ & $7,61 \mathrm{a}$ & $7,43 \mathrm{a}$ & $7,34 \mathrm{a}$ & $7,02 \mathrm{a}$ \\
$\mathbf{2 0}$ & $8,96 \mathrm{a}$ & $9,35 \mathrm{a}$ & $7,48 \mathrm{a}$ & $7,22 \mathrm{ab}$ & $2,22 \mathrm{~b}$ & $0,00 \mathrm{~b}$ \\
$\mathbf{4 0}$ & $7,85 \mathrm{a}$ & $8,78 \mathrm{a}$ & $6,76 \mathrm{~b}$ & $6,74 \mathrm{~b}$ & $0,00 \mathrm{~b}$ & $0,00 \mathrm{~b}$ \\
\hline \hline
\end{tabular}

Angka-angka sekolom yang diikuti huruf yang sama menunjukkan tidak berbeda nyata menurut DMRT 5\%.

Biota Vol. 12 (2), Juni 2007 


\section{Pengaruh bahan humat}

Penyertaan bahan humat berbeda dengan bahan organik, meningkatkan ketahanan hidup A. niger yang disertakan dalam pupuk pelet bio-fosfat selama proses pembuatan pupuk. Terdapat peningkatan jumlah $A$. niger hingga $24,4 \%$ pada perlakuan penyertaan bahan humat $10 \%$ (v/b). Pada perlakuan penyertaan bahan humat $20 \%$ jumlah $A$. niger yang bertahan hidup dalam pupuk pelet bio-fosfat cenderung mengalami penurunan, namun demikian secara statistik tidak menunjukkan perbedaan yang nyata dengan perlakuan penyertaan bahan humat 10\% (Gambar 2).

Perbedaan pengaruh penyertaan $\mathrm{BH}$ dan BOC terhadap ketahanan inokulum A. niger dalam pupuk bio-fosfat diduga disebabkan perbedaan tingkat ketersediaan nutrisi yang terdapat dalam bahan humat. Hal demikian menyebabkan tingkat pengaruhnya terhadap perubahan bentuk inokulum A. niger lebih kecil dibandingkan BOC. Selain itu, bahan humat merupakan produk akhir dekomposisi bahan organik sehingga memiliki stabilitas lebih tinggi dibandingkan bahan organik segar atau disebut active or labile organic matter (Stevenson, 1994; Vaughan \& Ord, 1985) sehingga lebih mampu melindungi inokulum $A$. niger pada saat digabungkan dan dibuat pupuk pelet bio-fosfat.

\section{Pengaruh suhu pengeringan}

Suhu pengeringan berpengaruh terhadap jumlah $A$. niger yang bertahan hidup dalam pupuk pelet bio-fosfat. Terdapat peningkatan jumlah $A$. niger pada perlakuan suhu $60^{\circ} \mathrm{C}$, selanjutnya semakin tinggi suhu pengeringan maka jumlah $A$. niger nyata semakin berkurang (Gambar 3). Pada suhu $60^{\circ} \mathrm{C}$ terdapat peningkatan jumlah $A$. niger, namun secara statistik tidak berbeda nyata dengan perlakuan suhu $50^{\circ} \mathrm{C}$. Peningkatan tersebut kemungkinan disebabkan oleh adanya induksi terhadap perkecambahan spora A. niger selama proses pembuatan pupuk.

\section{Pengaruh interaksi}

Berdasarkan hasil uji interaksi antarperlakuan, terlihat bahwa ketahanan hidup inokulum A. niger dalam pupuk pelet bio-fosfat lebih dipengaruhi oleh keberadaan bahan organik dan tingkat suhu pengeringan. Semakin tinggi penyertaan bahan organik dan suhu pengeringan, ketahanan hidup inokulum A. niger dalam pupuk bio-fosfat semakin rendah. Keberadaan bahan organik dalam formula pupuk pelet bio-fosfat mutlak diperlukan sebagai sumber nutrisi $A$. niger pada saat pupuk tersebut diaplikasikan. Oleh sebab itu, suhu pengeringan pupuk pelet biofosfat yang ideal adalah berkisar 50 hingga $60^{\circ} \mathrm{C}$.

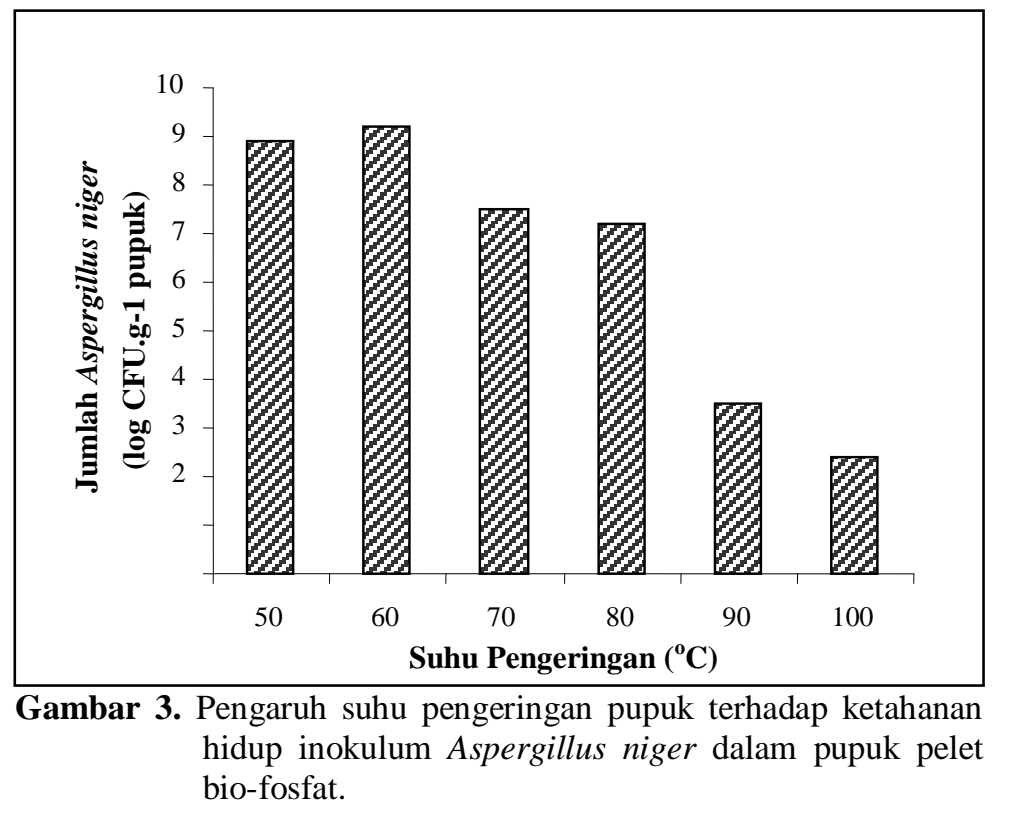




\section{Kesimpulan}

Berdasarkan hasil pengujian yang telah diuraikan di atas, dapat disimpulkan bahwa penyertaan bahan organik dan suhu pengeringan pupuk nyata mempengaruhi ketahanan hidup inokulum Aspergillus niger selama proses pembuatan pupuk pelet biofosfat. Jenis bahan organik yang tidak mudah tersedia untuk $A$. niger dan waktu pengeringan pupuk yang lebih cepat merupakan cara yang paling tepat untuk mendukung stabilitas dan ketahanan inokulum A. niger yang disertakan dalam pupuk pelet bio-fosfat.

\section{Daftar Pustaka}

Atlas, R.M. and Bartha, R. 1987. Microbial Ecology. Fundamental and application. The Benjamin/Cummings Publishing Company, Inc. California.

Balasubramanian, V., Singh, L. and Nnadi, L.A. 1980. Effect of long term fertilizer treatment on groundnut yield, nodulation and nutrient uptake at Samaria, Nigeria. Plant and Soil 55: 171-180.

Banik, S. and Dey, B.K. 1982. Available phosphate content of an alluvial soil as influenced by inoculation of some isolated phosphatesolubilizing microorganisms. Plant and Soil 69: 353-364.

Elfiati, D., Husin, E.F., Hakim, N. dan Kasli. 1999. Kajian efisiensi pemupukan $\mathrm{P}$ terhadap hasil tanaman jagung dengan pemanfaatan jamur pelarut fosfat pada oksisol yang dilacak dengan $\mathrm{P}^{32}$. J. Studi Pertanian-Pascasarjana UNAND 1: $1-6$

Gaind, S. and Gaur, A.C. 1991. Thermotolerant phosphate solubilizing microorganism and their interaction with mung bean. Plant and Soil 133: 141-149.

Goenadi, D.H. dan Saraswati, R. 1993. Kemampuan melarutkan fosfat dari beberapa isolat fungi pelarut fosfat. Menara Perkebunan 61 (3): 6166.
Goenadi, D.H. 1996. Pemanfaatan mikroba pelarut fosfat dalam pembuatan pupuk bio-P. Warta Puslit Biotek. Perkebunan II (1): 43-48.

Kim, K.Y., Mc Donald, G.A. and Jordan, D. 1997. Solubilizationof hydroxyapatite by Enterobacter agglomerans and cloned Escherchia coli in culture medium. Plant and Soil 24: 347-352.

Rao, N.S.S. 1976. Field response of legumes in India to inoculation and fertilizer application. In: Nutman P.S. (Eds.). Symbiotic nitrogen fixation in plant. Cambridge University Press, Cambridge.

Rao, N.S.S. 1982. Biofertilizers in Agriculture. Oxford \& IBH Publ. Co., New Dehli.

Rao, N.S.S. 1994. Mikroorganisme dan Pertumbuhan Tanaman. Edisi kedua. UI-press, Jakarta.

Salih, H.M., Yahya, A.I., Abdul-Rahem, A.M. and Munam, B.H. 1989. Availability of phosphorus in a calcareus soil treated with rock phosphate or superphosphate as affected by phosphatedissolving fungi. Plant and Soil 120: 181-185.

Stevenson, F.J. 1994. Humus Chemistry. Genesis, composition, reaction. Second edition. John Willey and Sons Inc. New York.

Thomas, G.V., Shantaram, M.V. and Sharaswathy, N. 1985. Occurrence and activity of phosphatesolubilizing fungi from coconut plantation soils. Plant and Soil 87: 357-364.

Vaughan, D. and Ord, B.G. 1985. Soil organic matter-a perspective on its nature, extraction, turnover and role in soil fertility. In: Vaughan, D. and Malcolm, R.E. (Eds.). Soil Organic Matter and Microbial Activity. Martinus Nijhoff/DRW. Junk Publisher, Dordrecht.

Walter, J.F. and Pauu, A.S. 1993. Microbial inoculant production and formulation. In: Meeting Jr, F.B. (Eds.). Soil microbial ecology applications in agriculture and environmental management. Marcel Dekker, New York.

Zhang, F.S., Ma, J. and Cao, Y.P. 1997. Phosphorous deficiency enhances root exudation of lowmolecular weight organic acids and utilization soluble inorganik phosphate by radish (Rhaganus sativus L.) and rape (Brassica napus L.) plants. Plant and Soil 196: 261-264. 